\title{
DESENVOLVIMENTO SUSTENTÁVEL: A NORMA JURÍDICA AMBIENTAL E O DESENVOLVIMENTO ECONOOMICO
}

Ana Claudia Duarte Pinheiro*

SUMÁRIO. 1. Introdução. 2. O Interesse Secundário. 3. A Sobrevivência do Homem. 4. A Identificação Econômica. 5. A Norma Juridica Ambiental. 6. A norma ambiental em âmbito de MERCOSUL. 7. Conchusão. 8. Bibliografia.

SUMMARY: 1. Introduction. 2. The Secondary Interest. 3. The Survival of men. 4. The Economical Identification. 5. The Environmental Jutidical Norm. 6. The Environmental Norm in MERCOSUL ambit. 7. Conclusion. 8. Bibliography.

SUMARIO: 1. Introducción. 2. El Interés secundario. 3. La Sobrevivencia del hombre. 4. La Identificación Económica. 5. La Norma Jurídica Ambiental. 6. La Norma Ambiental en el ámbito del MERCOSUR. 7.Conclusión. 8. Bibliogtafia.

RESUMO: A humanidade vem, a partir da segunda metade do século XX, tomando conhecimento de todos os problemas decorrentes dos prejuizos ambientais causados pelos desmandos do próprio homem que já se conscientizou de seus atos maléficos, mas não mudou efetivamente suas ações. Há muitos interesses em jogo e são muitas as questöes pertinentes à matéria, além da jurídica, como a economia, a sociologia, a filosofia etc. Aspecto, porém, de vital importância dizem respeito à norma jurídica ambiental e que exigem amadurecimento legislativo de cada um dos Estados e deles enquanto protagonistas do desenvolvimento sustentável. A questão implica em transnacionalidade de interesses muitas vezes divergentes e culmina com a necessidade de harmonização legislativa de tal forma que os blocos regionais, em especial o MERCOSUL, se concentrem de forma equilibrada nos objetivos propostos quando de sua criação.

ABSTRACT: Since the middle of the $X X$ century, mankind has become

"Mestranda em Direito Negocial pela Universidade Estadual de Londrina - UEL. Docente da UEL e da UNIFIL 
aware of all problems decurrent of environmental injuries caused by the excess of men themselves, who have already become conscious of their harmful acts against the environment, but actually, they havent changed their acts. There are many interests involved and many questions related to this subject, besides the juridical, for instance: Economy, Sociology, Philosophy, etc., yet the vital aspect concens to the Environmental juridical Norm, demandind Legislative ripening of each and every State of the country and their commitment with the Sustainable Development. The question implies transnationality of interests, often divergent, and culminates on the necessity of Legislative harmonization, in which the regional blocks, especially MERCOSUL, should concentrate themselves in a well-balanced way on the objectives proposed when they were created.

RESUMEN: La humanidad a partir de la segunda mitad del siglo $X X$, viene tomando conocimiento de todos los problemas ocasionados en razón de los perjuicios ambientales causados por los desmanes del propio hombre que ya ha tomado consciencia de sus hechos maleficos, pero no ha cambia. do efectivamente sus acciones. Hay muchos inteteses en juego y son muchos los asuntos pertinentes a la materia, además de la jurídica, como la economía, la sociologia, la filosofia, etc. Este aspecto, sin embargo, de vital importancia se refiere a la noma furidica ambiental y que exige madurez legislativa de cada uno de los Estados y de ellos cono protagonistas del desarrollo sustentable. El asunto implica en transnacionalidad de intereses que muchas veces son divergentes y culmina con la necestad de una armonia legislativa de tal manera que los bloques regionales, en especial el MERCOSUR, se concentren de una forma equilibrada en los objetivos propuestos en el momento de su creación.

PALAVRASCHAVES: Meio-ambiente. Noma junidica ambiental. MERCOSUL. Desenvolvimento sustentável.

KEYWORDS: Environment. Environmental Juridical Norm. MERCOSUL. Sustainable Development.

PALABRAS-LLAVE: Medio ambiente. Norma juridica ambiental. MERCOSUR. Desarrollo sustentable. 


\section{Introdução}

A humanidade vem vivenciando, nos últimos anos, especial interesse pelo tema ambiental. Quando se apercebeu da degradação operada pelas mãos do homem e, também, da impossibilidade de recuperação do meio ambiente, iniciou, mais que depressa, estudos e ações com o objetivo de frear o desgaste até então imposto à natureza, em todos os cantos do planeta Terra.

Contudo não só mobilizada por tal constatação é que se iniciaram os estudos e as ações em prol da preservação do planeta, mas principalmente pelo reconhecimento de que os desmandos do homem, resultavam em prejuízo à sua própria sobrevivência.

A criação de leis foi uma das alternativas apresentadas para alcançar o objetivo precípuo de preservação ambiental. Naturalmente há um marco, a contar do final da primeira metade de século XX, nas legislações dos países de um modo geral. Antes disto as leis não tinham a intenção efetiva e específica de proteção ao meio ambiente, mas sim de regular a conduta humana por motivos diversos.

Após a realização de eventos de natureza internacional, como a Declaração Universal do Meio Ambiente, oriunda da Conferência das Nações Unidas, realizada em Estocolmo, na Suécia, em 1972, é que se debruçou sobre a questão ambiental, grande parte da Sociedade Internacional.

Os países passaram a criar leis de proteção à natureza, à fauna, à flora, aos recursos naturais, enfim a tudo, ou quase tudo que diz respeito à natureza e à sua proteção. $\mathrm{O}$ comportamento no que diz respeito aos recursos naturais passou a ter tal importância que não poderia deixar de ser regulado por leis.

É válido considerar que o império da lei recai sobre o comportamento, exigindo que o homem norteie sua conduta, visando o meio ambiente sadio, por ser um direito de todos os seres humanos. Esta vem sendo a tônica da inquietação de toda a humanidade.

O debate está aberto. Nele são colocados questionamentos conceituais de importância mundial, que enveredam por aspectos de natureza jurídica, econômica e social, abordando-se constantemente temas como a qualidade de vida, desenvolvimento sustentável, dignidade da pessoa humana, preservação e princípios ambientais, e também, os conflitos de interesses e leis entre as nações. 


\section{O Interesse Secundário}

Aspectos econômicos e financeiros estão, hoje, agregados ao conceito de meio ambiente. Ao mencionar a necessidade de preservação ambiental, a condição fundamental à sobrevivência humana não se restringe ao meio ambiente sadio, mas também a situação econômica e financeira que lhe permita um crescimento pessoal, que proporcione a toda sociedade o chamado desenvolvimento sustentável, conceito recente e que incorporou grande importância no mundo todo e inclusive no Brasil.

Para o desenvolvimento econômico, nestes novos tempos em que o meio ambiente incorporou grande importância, espera-se um novo tratamento aos recursos naturais esgotáveis, assim como ao lixo, aos resíduos e detritos decorrentes de atividades poluidoras ou não, aos crimes e danos ambientais e aos agentes direta ou indiretamente envolvidos em todas as ações que reflitam interferência ambiental negativa.

Cada vez mais a humanidade se dá conta e verifica o quão próximas estão as questões ambientais e as questões econômicas. Afirma Fabíola Santos Albuquerque':

Desenvolvimento econômico e meio ambiente são interdependentes, caminham lado a lado. A correlação é percebida a olhos vistos. Até hoje, nenhuma construção prática foi capaz de isolálos, no que tange à não-incidência de efeitos. Trata-se de uma relação reflexiva, de uma reação circular.

Vislumbra-se, porém, que a humanidade não alcançou um pensamento tão progressivo. Apesar das inúmeras e honrosas tentativas promovidas ao longo das duas últimas décadas do século $\mathrm{XX}$, o que se verifica é que a preservação ambiental não é um interesse de primeira grandeza para nenhum dos povos ditos "civilizados" que compõem o planeta Terra.

1 ALBUQUERQUE, Fabiola Santos, O meio ambiente como objeto do direito no Mercosul, in Revista de Informaçăo Legislativa, out/dez 2000 , ano $37, \mathrm{n}^{3} 149$, pág. 265 a 274 , Senado Federal, Brasília., pág. 267 274 


\section{Afirma Arnaldo Godoy²:}

Em termos mais explícitos, a humanidade protege a natureza porque a natureza protege a humanidade. Um temor apocaliptico oxigena o ambientalismo. Surge uma racionalidade econômica a gerir o meio ambiente. Traduzida em cálculos de custo e beneficio.

A questão econômica envolvendo o tema ambiental traduz, ainda, a conotação do interesse pelo interesse, unicamente. Isto é, o homem somente visa a preservação do meio ambiente como princípio secundário a the proporcionar bens apreciáveis economicamente e não como segmento determinante e razão direta de sua sobrevivência.

A legislação ambiental interna sofre as conseqüências dos interesses que permeiam a questão, como afirma mais uma vez, Fabiola Santos Albuquerque $e^{3}$ :

Infelizmente, constata-se que o plano teórico corre a passos lentos do plano real. Isso é claramente percebido quando nos deparamos com situações concretas e percebemos o quanto a legislação ambiental é vítima de todas as querelas e lentidão legislativa.

O interesse, ao que parece, é efetivamente a exploração econômica, buscando a sobrevivência de forma selvagem e egoísta, impondo seus interesses próprios em detrimento dos demais e, pior, independentemente do grau de prejuízo ocasionado por tal comportamento nefasto. Ain$\mathrm{d}$ a que isto venha a the afetar de forma direta, futura ou mesmo imediatamente, não demonstra, o homem, qualquer intenção de modificar seu comportamento.

Estudos há referentes à questão ambiental e sua influência econômica sobre a atividade empresarial e que se ocupam em demonstrar ângulos relativos a internalidade ou externalidade dos efeitos positivos ou negativos impostos a uma determinada comunidade.

Eduardo Nascimento da Costa ao analisar a questão afirma:

Os custos associados a uma atividade econômica dependem da ótica sob a qual analisamos a organização. Os custos internos, ou aqueles que são suportados pela empresa no processo de produção. São muito bem calculados e determinados pela Contabilidade de Custos e Contabilidade Gerencial.

GODOY, Arnaldo Moraes, Fundamentos Filosóficos da Proteção Ambiental, www.arnaldogodoy, avd.br, mar. 2001, Londrina, página 2

"Ib idem, pág. 272.

+ COSTA, Edaardo Nascimento, O papel da contabilidade como ciência geradora de informaçóes na sustentaçấo de um posicionamento estratégico da empresa frente às questôes ecologicas, Dissertaçüo de Mestrado, Universidade Norte do Paraná, UNOPAR, Londrina, 2001, página 48. 
Nesse caso, se apenas os custos internos forem considerados, a análise tem um caráter privado. Por outro lado, se o conceito de "custos" for ampliado, considerando também os custos que terceiros suportam em todo o ciclo de vida do produto, a análise terá um caráter social.

A questão analisada sob o prisma econômico, muitas vezes é vista de forma imediatista. $O$ prejuizo ambiental com alto reflexo social é compensado pelo lucro instantâneo, sob a justificativa do progresso e do pretenso afastamento da miséria. O respeito à lei pode representar qualquer desequilíbrio econômico, portanto é comum a opção pelo dano ao meio ambiente em descumprimento à norma legal.

Assim, muitas indústrias brasileiras e outras tantas estrangeiras que vieram para o Brasil e instalaram-se em diversos Estados, mediante incentivos que refletiram positivamente na lucratividade da atividade, pouco ou nada fizeram para evitar o prejuizo ambiental. A criação de empregos e a influência sobre a economia de muitos Municípios e Estados têm sido suficientes para justificar o dano ambiental.

Afirma Eduardo Nascimento da Costa que "Quando uma empresa se instala em determinada comunidade, apesar de sob a ótica privada ela poder ser altamente lucrativa e viável, pode também causar um impacto nocivo sobre essa comunidade que, sob a ótica social, ela se torna prejudicial". 5

Os efeitos positivos efetivamente sentidos pela população, que se traduzem principalmente na geração de empregos, não refletem com fidelidade os danos assimilados ao longo do tempo. Os prejuizos ambientais ocasionados pela nova atividade e que em muitas oportunidades não são suportados pelas empresas, somente pelos cidadãos, levam o saldo da comunidade para o vermelho, a despeito da altíssima lucratividade da atividade empresarial.

Neste impasse entre o desenvolvimento econômico, científico e tecnológico e a preservação ambiental o conceito de desenvolvimento sustentável, determinado pela Comissão Mundial de Meio Ambiente, como sendo "aquele que atende às necessidades do presente sem comprometer a possibilidade de as gerações futuras atenderem às suas próprias necessidades", "fica pairando nebulosamente sobre a humanidade.

Portanto, todos os esforços para que a adoção de formas racionais de exploração da natureza utilizando-se tecnologias não-predatórias a fim de preservar o equilíbrio ecológico, representam o mínimo diante do grande contingente de ações contrárias. 


\section{A Sobrevivência do Homem}

O que podem então esperar as futuras gerações, para que se instaure o verdadeiro desvê-lo da atual, no sentido de cumprir a letra estabelecida? A lição de Édis Milaré, mostra sem falso otimismo:

... é que a espécie humana e a Terra encontram-se num determinado estágio de evolução, impossível de precisar no qual dispomos de razoáveis informações retrospectivas sobre o caminho percorrido e, como meras hipóteses, de prospectivas sobre um futuro impreciso e de horizonte curtíssimo.

Tem sido intensa a produção legislativa no Brasil e no mundo. Muito se tem discutido sobre a preservação ambiental e as leis esparsas e muitas vezes confusas, vem sendo produzidas, embora muitas vezes se apresente situações caóticas de trágicos acidentes ambientais.

A Constituição Federal mostrou-se um avanço em termos nacionais. Esclarece Fabíola Santos Albuquerque que :

A nossa Carta Magna de 1988 representou um marco para o meio ambiente. Pela primeira vez na história constitucional foi destinado um capítulo inteiro à matéria, claramente influenciado pelos princípios expressos na Declaração Universal do Meio Ambiente (72), sem contar com as inúmeras referências disseminadas ao longo do texto, dando-lhe um jaez progressista e paradigmático, e embuído da tendência internacional de celebrar o meio ambiente como direito comum a todos os povos e como pré-requisito essencial à sadia qualidade de vida, bem como a atribuição transindividual de preservá-lo às presentes e futuras gerações.

Esclarecimentos relativos às conseqüências decorrentes da poluição, do desmate, da devastação, da aniquilação da fauna, enfim de todas as questôes ligadas à conduta humana em prejuízo do ambiente, têm sido apresentados aos mais ricos e aos mais pobres representantes da Sociedade Internacional. A proteção constitucional e legal existe e é bem delineada em grande parte das nações desenvolvidas e em desenvolvimento.

Contudo, e mesmo assim, pouco se tem observado no sentido de estabelecer um compromisso comportamental que implique em preservação do meio ambiente segundo uma convicção incorporada por toda a sociedade. $\mathrm{Na}$ realidade, o que se percebe é que o discurso evidencia-se diferenciado da prática e a ordem normativa não confirma a conduta, a despeito da existência da sanção.

MLARE, Edis . Direito do Ambiente, $2^{2}$ ed: Rewista dos Tribunais, São Raulo, 2001, página 37. 


\section{Paulo de Barros Carvalho, explica a questão:}

A eficácia ou efetividade, por sua vez, diz respeito aos padrões de acatamento com que a comunidade responde aos mandamentos de uma ordem jurídica historicamente dada. Indicaremos como eficaz aquela norma cuja disciplina foi concretamente seguida pelos destinatários, satisfazendo os anseios e as expectativas do legislador, da mesma forma que inculcaremos de ineficaz aquel'outra cujos preceitos não foram cumpridos pelos sujeitos envolvidos na situação tipificada. Toda vez que a conduta estipulada pela norma for reiteradamente descumprida, frustrar-se-ão as expectativas, inexistindo eficácia social.

O que importa é a sobrevivência hoje, levando em consideração as características de imediatismo e às evidentes necessidades do ser humano, que muitas vezes o impedem de cumprir o dever estabelecido normativamente. O futuro pouco importa, pois a fome, a sede, o frio, estão se impondo hoje à humanidade. Amanhã ... fica para amanhã.

O mundo nunca viu tanta riqueza e tanta pobreza sobrevivendo juntas lado a lado. Nesse compasso, ricos e pobres vão sobrevivendo. Os primeiros impondo aos últimos as condiçōes de sua sobrevivência, usufruindo deles os sacrificios impostos ao meio ambiente. É um círculo vicioso, onde a própria humanidade se escraviza e se prejudica em nome de sua sobrevivência.

A realidade fotografada pela mente é de que os mais ricos parecem viver, enquanto os mais pobres parecem apenas sobreviver. Por isso é pouco importante cumprir a lei, vez que a sobrevivência está profundamente atrelada à questão ambiental.

\section{A identificação Econômica}

O tema tem merecido especial atenção das mais diversas áreas de conhecimento. Da cultura à ciência, da economia à saúde, a noção de meio ambiente e todas as suas peculiaridades, vem desempenhando papel de fundamental importância para um conjunto cada vez mais expressivo de interesses $\mathrm{em}$ todos os segmentos da sociedade.

Afirma Miguel Angel Del Arco Torres ${ }^{10}$ :

É tão sério o problema e tão variadas as perspectivas de análises, que a preocupação pelo cuidado de nosso meio ambiente se converteu em objeto das mais diversas disciplinas.

\footnotetext{
"CARVALHO, Paulo de Barros, Curso de Direito Tributário, 14\% ed., Editora Saraiva, 2002, São Paulo, pág. 81 * TORRES, Miguel Angel Del. El tributo como instrumento de proteçăo ambiental. Granada. Lael. Ed. 1998. Pấg. 1 "Es tan serio el problema y tan variadas lâs perspectivas de análisis, que la preocupación por el cuidado de nuestro entomo natural se ha convertido en objeto de las más diversas disciplinas. 278
} 
Ao tratar do meio ambiente o artigo 225 da Constituição Federal, determina-o como sendo um bem jurídico que a todos pertence, e, por conta de exercer plenamente tal propriedade, todos devem preservá-lo, utilizando e usufruindo de forma limitada, respeitando os demais interessados.

A preservação do meio ambiente encontra-se explícita no Diploma Maior brasileiro, como sendo uma responsabilidade do Poder Público e da coletividade. Portanto, no mesmo dispositivo constitucional, ao homem foi concedido o exercício do meio ambiente, tanto quanto imputada a obrigação de preservá-lo.

Tal situação relativiza as condições de todos no que pertine ao meio ambiente, pois nem o Poder Público, nem o homem, têm a possibilidade de impor sacrificios ambientais que provoquem danos ao meio ambiente e, conseqüentemente, prejuizos à humanidade em proveito de um ou alguns. Esta é a máxima imposta pela Constituição Federal que decorre de uma premissa de âmbito internacional, decorrente da Declaração Universal do Meio Ambiente.

Neste sentido afirma Miguel Angel Del Arco Torres ${ }^{11}$ :

Oconflito entre a proteção do meio ambiente e odesenvolvimento econômico se tem relativizado, já que hoje podemos assegurar que a solução se encontra no equilibrio entre ambos valores, o qual se denomina "Desenvolvimento sustentável"

Considerando a prescrição constitucional que a todos permite desfrutar da imensidão ambiental com critérios e limitações, caberá a todos - cidadãos e Estado - o direito de encontrar no sistema judiciário a proteção contra lesão ou ameaça que, eventualmente, o Estado ou qualquer cidadão venha a impor contra o meio ambiente.

A Constituição Federal determina a possibilidade de exercer, por intermédio do Judiciário, o direito de ação, encontrando-se no artigo $5^{\mathrm{a}}$, inciso XXXV a garantia necessária ao seu efetivo exercício em proteção ao meio ambiente, resguardando o presente e o futuro da humanidade.

O exaurimento dos recursos naturais demarca preocupação, também, com o desenvolvimento da economia. Se até agora o homem sugou tudo o que o meio ambiente podia lhe proporcionar em prol de satisfazer suas ambições, muitas além de suas efetivas necessidades, agora é imprescindivel que o homem aprenda que a riqueza e o desenvolvimento estão na preservação do meio ambiente.

A lição de Fabíola Santos Albuquerque ${ }^{12}$ confirma: não há como impedir nem tão pouco é interessante a estagnação econômica em prol do meio ambiente, como também não pode haver um ganho econômico indiferente àquele.

"Ib idem. Pág. 304

${ }^{12}$ ALBUQUERQUE, Fabíola Santos, Direito de propriedade e meio ambiente, $1^{2}$ ed. Juruá, 1999, página 93 
A atuação econômica não se encontra independente da preservação ambiental, embora o desequilíbrio esteja, ainda, evidente para todos. É imprescindivel que o homem alcance um modelo de desenvolvimento compatível e equilibrado com as necessidades impostas pela natureza, sob pena de acabar com o seu próprio futuro e, por conseqü̈ência, para o restante dos seres vivos.

O tema não se restringe a conceitos de ordem jurídica apenas. Maria Luisa Faro Magalhães afirma o envolvimento de "uma multiplicidade de questões"13, $\mathrm{C}$ também a uma infinidade de conhecimentos inesgotáveis que certamente promoverão inúmera informações e outros conhecimentos.

A autora ao demonstrar a importância da economia menciona Martin Rodk que ao analisar a temática ecológica do ponto de vista antropológioo e ético na obra Ecologia e Economia, aponta a identidade concertual com a ecologia. Neste passo, Maria Luisa transcreve ${ }^{14}$ :

... do ponto de vista léxico, ambas as áreas do conhecimento se ocupam de um mesmo objeto e são oriundas do mesmo radical "oikos", que significa "casa". A ecologia investiga as estruturas da organização da casa, enquanto a economia decifra a lei (nomos) para administração da mesma casa.

A proteção ao interesse de todos e à sobrevivência da espécie humana, exige que todos os mecanismos envolvidos com a questão ambiental sejam implementados de forma racional. Todas as áreas de conhecimento que direta ou indiretamente espelham as vantagens e prejuízos decorrentes da ação humana sobre o meio ambiente merecem ser analisadas, sempre que possível de forma concomitante e com profundidade.

Retomando a expressão relativa à sustentabilidade do progresso, afirma José Marcos Domingues de Oliveira ${ }^{15}$ :

Desenvolvimento sustentável consiste no progresso da atividade econômica compatível com a utilização racional dos recursos ambientais. Representa a rejeição do desperdício, da ineficiência e do desprezo por esses recursos. E a ciência tem mostrado, por exemplo, a viabilidade da substituição dos pesticidas (que geram intoxicação humana e poluição de águas superficiais e interiores) pelo controle biológico de pragas nas lavouras; a reciclagem de diversos materiais como metais, vidros, papéis e até plásticos; a substituição de combustiveis fósseis (reconhecidamente limitados e poluidores) por combustiveis renováveis, de fontes infinitas e não-poluentes.

\footnotetext{
1.3 MAGALHÃES, Maria Lúsa Faro, Responsabilidade civil por danos patrimoniais a recursos naturais difusos: o óbice da quantificą̧ão, Tese de Doutorado, Pontificia Universidade Católica de São Paulo, 2002, página 73

Ho idem, pigina 73

is OLIVEIRA, José Marcos Domingues de. Direito tributário e meio ambiente: proporcionalidade, tipicidade aberta, afetaçăo da recelta. Rio de Janeiro. Renovar. 1995. Pág. 12 
O desenvolvimento econômico é pressuposto para o progresso e o afastamento da pobreza. A atualidade das relações internacionais assim determina de tal sorte que as nações impõem sua independência segundo o seu próprio desenvolvimento, que se determina, também, pelas condições de vida das pessoas, não apenas em termos econômicos, mas também tomando em consideração a qualidade ambiental. Tudo de forma comparativa - países em desenvolvimento com suas peculiaridades em relação aos países desenvolvidos, com suas particularidades.

As dificuldades a serem transpostas pelos países em desenvolvimento são significativas, como afirma Ricardo Bicudo ${ }^{16}$ :

As condições atuais que enfrentam para viabilizar projetos de infraestrutura são barreiras dificeis de serem transpostas. Pelo menos três merecem atenção: usam modelos de engenharia inadequados à sua realidade, em geral adaptados ao Primeiro Mundo; estão sob a vigência de uma ordem econômica complexa e cruel - a economia de mercado -, que impóe verdadeiros malabarismos no ajuste de parâmetros técnicos e econômicos às leis do deus mercado, e encontram-se sob o jugo imaturo e dispendioso dos licenciamentos ambientais, o principal objeto das discussões da hora.

As discussões em torno da questão ambiental demonstram o embate de interesses que permeia o desenvolvimento econômico e a preservação do meio ambiente. A natureza somente terá vez quando o homem também tiver, como afirma, Ricardo Bicudo que "O homem só protegerá a natureza na medida em que se sentir protegido na sociedade em que vive."17

A estruturação de políticas públicas equilibradas que tenham como orientação a preservação do meio ambiente, mediante a contabilização dos prejuízos ambientais, dos custos de recuperação, ou mesmo dos investimentos realizados em proteção da natureza, tanto pelo Poder Públi$\mathrm{co}$, quanto por particulares, certamente resultarão de normas jurídicas que, porém não terão o condão de transformar a realidade atual.

\section{A Norma Jutídica Ambiental}

O sistema normativo positivado prescreve condutas específicas que dirigem o comportamento social. Afirma Paulo de Barros Carvalho que "... as normas juridicas formam um sistema na medida em que se relacionam de várias maneiras, segundo um princípio unificador." ${ }^{18}$

"GAZETA MERCANTIL Bicudo, Ricardo. pág. A-3. 26.01.2004.

"Ib idem, pág. A-3

"Ib iden, pág. 132 
O sistema é caracteristicamente dinâmico, embora sofra de dificuldades já anteriormente mencionadas neste texto, no que se refere à prescrição legislativa, vez que o processo de criação até a aprovação de lei é lento $\mathrm{e}$, muitas vezes, reflete interesses divergentes, mesmo que em plena concordância com a Carta Fundamental.

Adstrita ao sistema, a lei tem um campo de aplicação previamente limitado. Afirma André Franco Montoro que "Toda norma juridica tem, assim, um âmbito temporal, espacial, material e pessoal, dentro dos quais ela tem vigência ou validade." 19

A limitação, porém, não protege a norma dos eventuais conflitos. Especialmente nestes tempos em que as naçóes e os povos desenvolvem toda a sorte de negócios que não se restringem mais a um espaço físico específico e limitado.

Aliás, o que existe hoje é o desenvolvimento exacerbado de relações existentes desde as mais priscas eras. $O$ homem nunca ficou recluso a um espaço físico determinado. A própria sobrevivência lhe exigia buscar novos horizontes

A lei, de um modo geral, realiza o seu objetivo de proteger os interesses, em razão de suas características de generalidade e abstração, dentre outras, e segundo a interpretação mais adequada, poderá ser utilizada sempre que houver conflito.

A norma é de vital importância para delimitar o comportamento. Eventos internacionais, vêm se traduzindo em paradigmas da condição do Direito de um modo geral e em relação ao meio ambiente. José Mar$\cos$ Domingues de Oliveira ao mencionar sobre os preparativos da Eco92 afirma ${ }^{20}$ :

Um ano antes, em evento preparatório à Conferência, reunira-se no Rio de Janeiro a CONFERÊNCIA INTERNACIONAL DE DIREITO AMBIENTAL, comprometendo a comunidade jurídica nacional e estrangeira com a busca de um futuro melhor, em cujo esforço é imprescindível o concurso do Direito como instrumento regrador da conduta humana, não só estratificando padrões éticos consolidados, como apontando diretrizes e metas para a satisfação dos anseios mais profundos do Homem.

\footnotetext{
19 MONTORO, André Franco. Introduçăo a Ciência do Direito. São Paulo. $25^{\circ}$ edição, Editora Revista dos Tribunais. 2000.

20 idem. Pág. 8
} 
O ordenamento jurídico, diante dos caminhos que o homem vem percorrendo, transcende as fronteiras dos Estados com um enorme poder de produzir novas perspectivas à humanidade. Para José Marcos Domingeis de Oliveira “... o Direito é poderosa ferramenta de transformação." "21

Importa ressaltar que nas relações internacionais, muitas vezes, mais de uma legislação deve ser apreciada. Conforme André Franco Montoro ${ }^{22}$ :

... o fenômeno moderno da multiplicação de relações jurídicas em que figuram pessoas, bens ou atos regidos por legislaçôes de países diferentes dentro da comunidade internacional, coloca, com freqüência, o problema de se determinar qual a lei aplicável em cada caso. Trata-se do problema do conflito das leis no espaço...

A norma jurídica ambiental, assim como as demais normas, cumpre as suas determinaçōes segundo o ordenamento a que pertence. E um componente do sistema e segundo André Franco Montoro "Toda lei, em princípio, tem seu campo de aplicação limitado no espaço pelas fronteiras do Estado que a promulgou. Chama-se a isso territorialidade da lei." 23

Há oportunidades, contudo, em razão da expressiva carga de relaçóes negociais internacionais, em que as leis estrangeiras podem ser aplicadas em território nacional e vice-versa. Isto se configura por conta da necessidade de oportunizar a facilitação das relaçōes internacionais. O que vem sendo implementado por grande número de Estados.

A questão ambiental, por sua vez, transcende as fronteiras territoriais de um país. O prejuízo ao meio ambiente não fica restrito a uma localidade, mas se propaga, sem que se possa estabelecer um limite e muitas vezes, é impossível identificar, de imediato a extensão dos danos e suas vítimas.

A norma jurídica ambiental não deve se ater apenas às conseqüências relativas ao prejuizo ocasionado to meio ambiente. Antes disto é necessário que busque regular as condutas que antecedem o dano. Afirma Fabíola Santos Albuquerque ${ }^{24}$ :

Muito mais que reparar danos, é muito mais eficaz e ambientalmente correta a prevenção, pois, em regra, as agressōes ao meio ambiente são de dificil ou impossível reparação, sem contar com as incertezas e os custos.

\footnotetext{
Tb idem. Pág. 8

22 $\mathrm{lb}$ idem, pag. 389

2: 1 b idem, pág396

$\mathrm{Cb}$ idem, pág. 271
} 
A despeito da orientação principiológica apresentada, o que se evidencia é o conflito entre normas de países diferentes, conforme Fabíola Santos Albuquerque ${ }^{25}$ :

Nem a relevância da matéria e o seu reconhecimento como tal o fazem escapar dos vícios do legislativo, principalmente se levarmos em consideração o compromisso assumido de harmonizar a legislação ambiental dos países do Mercosul.

Sem dúvida o sistema legislativo ambiental brasileiro, ainda que tenha marcados avanços, guarda dissonância com as necessidade atuais em nível internacional. Trata-se de um modelo arcaico impositivo da intervenção do Estado e que nega a existência do processo integracionista e dos tratados internacionais que possam cuidar da matéria ambiental com mais desvê-lo sem a perda da soberania.

\section{A norma ambiental em âmbito de MERCOSUL}

A criação do Mercado Comum do Sul - MERCOSUL, se deu mediante a assinatura do Tratado de Assunção na data de 26 de março de 1991. Para Assis de Almeida, ${ }^{26}$ representou um "acordo-marco", vez que estabeleceu mecanismos destinados à formação de uma zona de livre comércio e união aduaneira entre a Argentina, o Brasil, o Paraguai e o Uruguai.

Norteando o processo de integração, foram estabelecidas suas necessidades essenciais, dentre as quais destaca-se o desenvolvimento econômico com justiça social, a ser alcançado mediante a criação de meios para ampliar as dimensões do mercado de todos os signatários.

Para alcançar os objetivos estabelecidos no Tratado, em seu preâmbulo são ressaltados diversos aspectos. Com maior relevo ao presente ensaio, destaca-se a eficácia no aproveitamento dos recursos disponíveis e a preservação ambiental.

As discussões relativas ao tema meio ambiente no MERCOSUL vêm evoluindo para uma abordagem mais ampla e consistente com as atuais demandas de um mundo globalizado. A rigor os países signatários buscam o desenvolvimento segundo suas próprias necessidades, tendo como premissa a compatibilidade com o imperativo da preservação ambiental.

\footnotetext{
${ }^{25} \mathrm{Ib}$ idem, pág272

${ }^{26}$ ALMEIDA, José Gabriel Assis de. MeRCOSUL: Mamual de direito da integraçăo. Rio de Janeiro. Lúmen Júris. 2001, pảg. 9 
A partir da recomendação constante da Declaração de Taranco, assinada durante a Primeira Reunião de Ministros do Meio Ambiente do MERCOSUL, ocorrida nos dias 20 e 21 de junho de 1995, em Montevidéu (Uruguai), a Reunião Especializada de Meio Ambiente - REMA, foro de tratamento da temática ambiental no MERCOSUL, foi transformada no Subgrupo de Trabalho de Meio Ambiente (SGT - 6), subordinado ao Grupo Mercado Comum - GMC ${ }^{27}$.

Em 1995 a Resolução na 38 do Grupo Mercado Comum - GMC, delimitou alguns objetivos essenciais, como ressalta Larissa SCHIMIDT ${ }^{28}$ :

- propostas de eliminação para restrições não tarifárias;

- inclusão do custo ambiental nos processos produtivos e adoção de ISO 14000;

- criação de uma base de dados com referência à tecnologias ambientais favoráveis;

- otimização de qualidade comum ambiental.

Visando o cumprimento do plano de trabalho aprovado pelo GMCe as necessidades dele decorrentes, o SGT -6 yem realizando reuniões ordinárias desde a sua criação, de modo que já efetuou, não sem enfrentar algumas dificuldades, negociações relativas ao Protocolo Adicional ao Tratado de Assunção onde se estabeleceram políticas públicas de conservação, turismo e proteção à saúde.

Embora tendo por objetivo a definição de alguns aspectos relacionados ao Protocolo, o SGT- 6, em reunião extraordinária, aprovou o Acordo - Quadro sobre Meio Ambiente do MERCOSUL ${ }^{29}$.

Realizada em março de 2001, na cidade de Florianópolis, a reunião marcou as discussões pontuando áreas de fundamental importância, como gestão sustentável dos recursos naturais, qualidade de vida e planejamento ambiental, destacando as seguintes premissas básicas ${ }^{30}$ :

- Ressaltar a necessidade de cooperar para a proteção do meio ambiente e para a utilização sustentável dos recursos naturais com vistas a alcançar a melhoria da qualidade de vida e o desenvolvimento econômico, social e ambiental sustentável;

- Estarem Convencidos dos benefícios da participação da sociedade civil na proteção do meio ambiente e na utilização sustentável dos recursos naturais;

\footnotetext{
27 www.mma.gov.br Mercosul/SGT6 Resumo Histórico, pág. 1

3* SCHIMIDT, Larissa. Panorama da Legislação ambiental do mercosul sob a ótica comparada dos principios ambientais europeus. In PIMENTEL, Luiz Otávio. Mercosul, Alca e Integração Euro-LatinoAmericana. Vol II, Guritiba, Juná, 2001. Pág, 92

"wi www mangov br Mercosul/SGT-6 Resumo Histórico. Pág.1

In idem. Pág 1
} 
- Reconhecer a importância da cooperação entre os Estados Partes com o objetivo de apoiar e promover a implementação de seus compromissos internacionais em matéria ambiental, observando a legislação e as políticas nacionais vigentes;

- Reafirmar os preceitos do desenvolvimento sustentável, preconizados na Agenda 21, adotada na Conferência das Nações Unidas sobre meio Ambiente e Desenvolvimento, em 1992;

- E Considerar que as políticas comerciais e ambientais devem complementar-se para assegurar o desenvolvimento sustentável dos recursos naturais dos Estados Partes.

O capítulo II do Acordo-Quadro sobre o Meio Ambiente do MERCOSUL estabelece ${ }^{31}$ :

... é o objetivo, a proteção do meio ambiente e o desenvolvimento sustentável mediante a articulação entre as dimensões econômica, social e ambiental, contribuindo para uma melhor qualidade do meio ambiente e de vida das populaçóes.

Sobre o trabalho do SGT - 6 na condução dos trabalhos relativos ao estabelecimento de políticas públicas, afirma Larissa Schimidt ${ }^{32}$ :

Por fim, pode-se dizer que a condução das politicas ambientais do processo de integração do MERCOSUL encontra-se "num plano mais virtual" do que efetivo. Isto se deve certamente à falta de abertura e participação social nas negociações. Algumas formas de participação ocorrem, mas são ainda muito incipientes. Os considerandos do Tratado de Assunção, assim como quase todos os documentos emitidos pelo SGT-6, abordam o objetivo da qualidade de vida das populaçōes dos páses do MERCOSUL. A harmonização é meio para se obter tal fim, mas só a efetiva participação é que reforçará o processo, hoje tão carente de legitimação social".

Sem dúvida o meio ambiente é um bem que deve ser tutelado de tal forma a permitir a preservação dos recursos naturais, esgotáveis ou não. $O$ Brasil, incorporou em sua Constituição Federal a previsão de dele desfrutar e o dever de protegê-lo. Outros países destacam, também, previsões semelhantes.

O MERCOSUL, por sua vez, vem demonstrando especial interesse pela problemática ambiental, contudo é ainda incipiente a atuação em prol do meio ambiente, especialmente em razão das legislações vigentes nos países signatários.

\footnotetext{
31 Www mma.gov.br Mcrcosul/SGT-6 Resumo Histórico, Pág* 2

32 Ib idem. Pág. 98 
As iniciativas mercosulinas permanecem apenas no plano das conjecturas e pouco se fez até o momento no sentido de ampliar e proceder ações efetivas no sentido de alcançar o desenvolvimento sustentável.

$O$ conflito ainda permanece. $O$ equilíbrio entre a proteção ao meio ambiente e o desenvolvimento econômico ainda não foi encontrado. Afirma Miguel Angel Del Arco Torres ${ }^{33}$ :

O Desenvolvimento sustentável se baseia em um vínculo essencial de cooperação do ser humano para com seus semelhantes com respeito a suas atividades e as conseqüências que estas podem trazer ao meio ambiente. Dito vínculo de cooperação representa a solidariedade coletiva, conceito que rege a preservação do meio ambiente e serve de fundamento da atuação do Estado para intervir na tarefa...

O evidente desequilíbrio manifestado pelo ordenamento jurídico do MERCOSUL, e confirmado pela inexistência de harmonização entre as legislaçốes, tanto na área do meio ambiente, onde a negligência na condução das políticas públicas é flagrante, como em outros segmentos.

A proposta mais adequada para interferência no modelo instalado é a de harmonização legislativa. Em termos de bloco regional como é o caso do MERCOSUL é imprescindivel oferecer maior contribuição no sentido de imprimir uma nova dinâmica legislativa a fim de obter resultados mais substanciais.

Embora mencionando a importância da harmonização legislativa, em especial para questões de natureza tributária, a lição de Maria de Fátima Ribeiro se coaduna, também, às peculiaridades da legislação ambiental ${ }^{34}$ :

Vale a pena ressaltar que a harmonização tributária não significa equalização total de alíquotas e bases tributárias em vários países e em todos os tributos. $O$ que se pretende é obter um mercado globalizado que seja consistente com o menor grau possível de distorções. Nesse sentido, há necessidade de aproximar a legislação tributária pertinente entre todos os paises membros do MERCOSUL.

O projeto ambiental não está restrito a um país ou a um bloco econômico. Exige a conscientização de todos os povos. A humanidade deve imprimir todos os esforços no sentido de preservação do meio ambiente, a fim de que as medidas de prevenção implementadas sejam suficientes para garantir à atual geração e às futuras uma qualidade de vida sadia.

\footnotetext{
"Ib Idem "El Desarollo sostenitle se basea em um vinculo esencial de cooperación Del ser humano para com sus semejantes com respecto a sus actividades y lls consecuencias que éstas puedan traer al medio ambiente. Dicho vinculo de cooperación representa la solidariedad colectiva, concetto que rige la preservación del medio ambiente y sirve de fundamento de la actuación del Estado para intervenir en tal tarea ..." Píg. 304

${ }^{34}$ RIBEIRO, Maria de Fátima. Considerações sobre a supremacia dos tratados internacionais sobre a legislação brasileira: O caso do MERCOSUL, jus navigandi, pág.1, 2001
} 
Em termos de bloco regional, como o MERCOSUL, a integração é, na atualidade, o caminho para o desenvolvimento, contudo, a sustentabilidade do progresso certamente se consubstancia mediante a cooperação entre os Estados em todos os aspectos sendo o meio ambiente um dos mais relevantes.

\section{Conclusão}

A realidade ambiental tem apresentado diversos matizes que sequer foram explorados, outros tantos que apesar de significativamente pesquisados, merecem, ainda, a atenção dos estudiosos das mais diversas áreas das ciências, em razão das transformações que se operaram no mundo desde que o Meio Ambiente passou a ter a consideração maior no sentido de preservação da vida humana no planeta.

$\mathrm{O}$ conhecimento da área envolve inúmeros conceitos não apenas jurigenos, mas também outros que não devem ser desprezados, pois trata-se de um segmento abrangente que exige dedicação tal no sentido de decifrar os aspectos norteadores do contexto histórico, sociológico, sócioeconômico etc., e que interessam à humanidade, pela influência direta que tem sobre a vida do homem de dos demais seres de todo o planeta.

O prejuízo ambiental se subdivide em duas vertentes: o prejuízo nefasto ao ambiente propriamente dito, que pode até culminar com a extinção da flora e da fauna e que tem como conseqüuência a extirpação definitiva da vida humana na face da terra e o prejuízo econômico diante da ação que visa alcançar beneficios a despeito dos prejuízos alheios. Prejuízos estes que atingem diretamente o ser humano e lhe degradam a sobrevivência.

$O$ reconhecimento da relaçäo existente entre os fatores de produção com os fatores sociais, políticos, filosóficos, sociológicos, históricos, econômicos, culturais, juridicos, ambientais etc., é condição fundamental para a mudança da mentalidade da humanidade.

Quanto ao dano ambiental é imprescindível reconhecer que nem sempre está restrito a um território especifico e, portanto, o campo de aplicação da norma jurídica ambiental não deve, também, se restringir, sob pena de não atender ao objetivo para o qual foi criada.

Diante desta realidade, no que se refere às relações internacionais, é necessário o empenho no sentido de melhor adequar a questão ambiental à questão legislativa. Caso contrário tanto o Brasil quanto o Mercosul permanecerão na contramão da história, no que se refere às naçôes em processo de desenvolvimento.

O desenvolvimento sustentável representa, portanto, a soma das alternativas encontradas para a preservação do meio ambiente e o progresso econômico sem prejuízo ambiental, com justiça social, incluído-se a 
este conjunto de fatores a harmonização da legislação interna com a internacional e a sua convergência, além do desenvolvimento científico, tecnológico, educacional, cultural etc., incorporado pelo homem a partir do momento em que se sinta confiante e seguro de seus direitos.

\section{BIBLIOGRAFIA}

ALBUQUERQUE, Fabíola Santos, Direito de propriedade e meio ambiente, $1^{\circ}$ ed. Juruá, 1999.

ALBUQUERQUE, Fabíola Santos, O meio ambiente como objeto do direito no Mercosul, in Revista de Informação Legislativa, Senado Federal, out/dez 2000, ano 37, n⿳⺈ 149, pág. 265 a 274, Brasília.

ALMEIDA, José Gabriel Assis de. MERCOSUL: Manual de direito da integração. Rio de Janeiro. Lúmen Júris. 2001.

CARVALHO, Paulo de Barros, Curso de Direito Tributário, 14ํe. ed., Editora Saraiva, 2002, São Paulo

COSTA, Eduardo Nascimento, O papel da contabilidade como ciência geradora de informações na sustentação de um posicionamento estratégico da empresa frente às questões ecológicas, Dissertação de Mestrado, Universidade Norte do Paraná, UNOPAR, Londrina, 2001.

GODOY, Arnaldo Moraes, Fundamentos Filosóficos da Proteção Ambiental, www.arnaldogodoy.avd.br, mar. 2001, Londrina.

MAGALHÃES, Maria Luísa Faro, Responsabilidade civil por danos patrimoniais a recursos naturais difusos: o óbice da quantificação, Tese de Doutorado, Pontifícia Universidade Católica de São Paulo, 2002.

MILARÉ, Édis . Direito do Ambiente, $2^{a}$ ed: Revista dos Tribunais, São Paulo, 2001.

OLIVEIRA, José Marcos Domingues de. Direito tributário e meio ambiente: proporcionalidade, tipicidade aberta, afetação da receita. Rio de Janeiro, Renovar, 1995

RIBEIRO, Maria de Fátima. Considerações sobre a supremacia dos tratados internacionais sobre a legislação brasileira: $O$ caso do MERCOSUL, jus navigandi, pág.1, 2001

TORRES, Miguel Angel Del. El tributo como instrumento de proteción ambiental. Granada. Lael. Ed. 1998.

www.mma.gov.br Mercosul/SGT-6 Resumo Histórico. 2003. 